\title{
OTIMIZAÇÃO DA ESCALA DE SERVIÇO DE UMA ORGANIZAÇÃO MILITAR
}

\author{
Diego Gonçalves Feijó \\ Universidade de Vassouras \\ Av. Expedicionário Osvaldo de Almeida Ramos, 280 - Centro, Vassouras - RJ, 27.700-000 \\ diego.g.feijo@gmail.com \\ Rafael Camargo Cardoso \\ Universidade de Vassouras \\ Av. Expedicionário Osvaldo de Almeida Ramos, 280 - Centro, Vassouras - RJ, 27.700-000 \\ rafaelkamargo@hotmail.com
}

\section{RESUMO}

Este trabalho desenvolve-se a partir da variação do efetivo de recrutas de uma Organização Militar, onde em determinados meses, seu efetivo não atende a demanda de seus postos de serviço, sendo assim, este te como objetivo otimizar a escala de serviço, a fim de respeitar uma folga de 48 horas para cada recruta durante estes meses proposta pelo Regulamento Interno de Serviços Gerais (inciso V do Art. 185 do Capítulo III). Para o desenvolvimento utilizou-se a Programação Linear através do Método Simplex, utilizando como tecnologia a ferramenta Solver do software Excel, a fim de obter a solução ótima do problema. Com a análise da solução ótima e um reajuste nos postos de serviço, respeitou-se a folga de 48 horas para cada militar e consequentemente maximizando a possibilidade quanto à produtividade desta Organização Militar.

Palavra-chave: Simplex; Maximização.

\begin{abstract}
This work develops from the variation of the recruitment of a Military Organization, where in certain months, its staff does not meet the demand of its service stations, so it is aimed at optimizing the service scale in order to respect a 48-hour break for each recruit during these months proposed by the Internal Regulation of General Services (item V of Article 185 of Chapter III). Linear Programming was used for the development using the Simplex Method, using as technology the Solver tool of Excel software, in order to obtain the optimal solution of the problem. With the analysis of the optimal solution and a readjustment in the service stations, the 48-hour gap was respected for each military and consequently maximizing the possibility of the productivity of this Military Organization.
\end{abstract}

Keywords: Simplex; Maximization.

\section{Como Citar:}

FEIJÓ, Diego Gonçalves; CARDOSO, Rafael Camargo. Otimização da escala de serviço de uma Organização Militar. In: SIMPÓSIO DE PESQUISA OPERACIONAL E LOGÍSTICA 
DA MARINHA, 19., 2019, Rio de Janeiro, RJ. Anais [...]. Rio de Janeiro: Centro de Análises de Sistemas Navais, 2019.

\section{INTRODUÇÃO}

O Exército Brasileiro é composto por Organizações Militares (OM), distribuídas nos 27 estados, divididos em várias qualificações, sejam elas artilharia, infantaria, intendência, material bélico, entre outras. Entretanto, por mais diversos que sejam os objetivos de cada OM, todas têm algo em comum: o serviço de guarda ou sentinela. $\mathrm{O}$ serviço de sentinela é julgado o ato mais importante no Exército Brasileiro, sendo julgado “os olhos da nação”. A sentinela é a responsável por fazer a segurança do local que está sob sua jurisdição, evitando desta forma invasões, seja pela fronteira ou ao aquartelamento, e principalmente o desvio de material classe V (armamentos e munições) para o narcotráfico.

Segundo o inciso V do Art. 185 do Capítulo III do Regulamento Interno de Serviços Gerais (RISG), "entre dois serviços de mesma natureza ou de natureza diferente, observarse-á, para o mesmo indivíduo, no mínimo a folga de quarenta e oito horas, sempre que possível." Contudo, nem sempre o efetivo pronto para o serviço é o suficiente para respeitar esta folga de quarenta e oito horas.

Este trabalho apresenta um estudo visando a otimização da escala de serviço de uma Organização Militar do Rio de Janeiro, localizada na Baixada Fluminense, que em certos meses não possui efetivo suficiente para atender a demanda de seus postos de serviço. Buscou-se levantar dados históricos do ano de 2016 a 2018 a fim de elaborar meios de respeitar os limites encontrados no problema.

A relevância deste estudo, além de buscar uma proposta a ser analisada pela Direção desta OM, busca cumprir as normas das Forças Armadas, aumentar a autoestima e o espírito de corpo destes militares e o aumento da produtividade das missões diárias da mesma.

\section{REFERENCIAL TEÓRICO}

\subsection{PESQUISA OPERACIONAL}

Segundo Marins [1], a Pesquisa Operacional é uma área da Engenharia de Produção que proporciona um procedimento organizado que auxilia na difícil tarefa de gestão financeira, de recursos humanos e de materiais de uma organização.

Para Belfiore e Fávero [2], a Pesquisa Operacional utiliza modelos estatísticos, matemáticos e algoritmos computacionais para tomada de decisões, atuando cada vez mais em um ramo multidisciplinar, envolvendo áreas como matemática aplicada, engenharia de produção, gestão de negócios e ciência da computação.

Longaray [3] afirma que o avanço da informática foi um grande aliado para a popularização da Pesquisa Operacional, e seu sucesso em âmbito empresarial se dá pela potencialidade de traduzir, de forma clara, objetiva e estruturada, as situações problemáticas vivenciadas diariamente na organização.

\subsection{MODELAGEM MATEMÁTICA}

A Modelagem Matemática, por sua vez, é uma técnica de ensino que para Boschi e Ferreira [4], permite aos alunos elaborar, construir, analisar e relacionar os conteúdos matemáticos ao seu dia a dia. Bassanezi [5] afirma que a Modelagem Matemática transforma problemas da realidade em problemas matemáticos, e são resolvidos interpretando suas soluções na linguagem do mundo real. 
Como os problemas desenvolvidos são de escolha e interesse do aluno, Burak [6] ainda afirma que o aluno desenvolve suas atividades mais entusiasmado, adquirindo prazer em estudar os temas da disciplina.

De acordo com D’ambrósio [7], a Modelagem Matemática torna o aluno mais consciente da utilidade da matemática para solucionar e analisar problemas cotidianos.

\subsection{LOGÍSTICA MILITAR}

Taguchi [8] descreve que a logística, a estratégia e a tática são os três ramos da arte da guerra, sendo a logística responsável por proporcionar aos outros dois ramos os meios necessários pela condução das operações militares.

Em um estudo realizado por McGinnis [9] sobre os princípios de logística militar, o mesmo afirma que a atividade logística deve ser flexível, sendo apta a responder às mudanças no ambiente externo à organização e às mudanças nos objetivos e planos da empresa e das parcerias estratégicas. O autor ainda afirma que, quando os recursos são limitados, é necessário indicar prioridades e alocações na coordenação dos processos logísticos com o intuito de assegurar que os objetivos organizacionais sejam atingidos.

\subsection{PLANEJAMENTO TÁTICO}

Enquanto o Planejamento Estratégico trabalha com objetivos à longo prazo e com ações e estratégias que afetam toda a organização, tendo sob sua responsabilidade os níveis hierárquicos mais elevados da empresa, o Planejamento Tático envolve objetivos de médio prazo, com ações que afetam somente parte da empresa, sendo desenvolvido pelos níveis intermediários da organização, afim de utilizar eficientemente os recursos disponíveis (ANDREUZZA, [10]).

Já Valentim [11] diz que a finalidade do Planejamento Tático é otimizar determinada área da organização e não ela como um todo, ou seja, trabalha com decomposições dos objetivos, estratégias e políticas definidas no Planejamento Estratégico. Sua função é fazer a aproximação do nível estratégico ao nível operacional, e pode-se considerar uma forma de alocação de recursos.

\section{METODOLOGIA}

Respeitando os critérios pré-estabelecidos pelo RISG, recomenda-se respeitar uma folga de no mínimo 48 horas para escalas de serviço. Alguns militares dormem somente duas horas por noite e quando esta folga não é respeitada, isto implica diretamente na produtividade das missões diárias. Esta alta carga de trabalho com poucas horas dormidas afeta também a autoestima do militar, já que o mesmo fica mais cansado, estressado e com pouco tempo para a família, afetando sua vida social. Segundo Martins e Kuhn [12], um estudo realizado na Austrália, com 20.820 jovens entre 17 e 24 anos, após um período de 12 a 18 meses, demonstrou que há um aumento de transtornos mentais comuns entre aqueles que dormem pouco. Cabe ressaltar que com folgas de vinte quatro horas, é impossível realizar o Treinamento Físico Militar, quesito importante para quem pleiteia engajamento.

Devido às altas horas de serviço e pouco tempo para descanso, alguns militares dormem em seus postos durante o serviço, e segundo o Art. 203 do Capítulo III do Código Penal Militar (CPM), quando o militar dorme em serviço de sentinela, vigia, plantão ou em qualquer serviço de natureza semelhante, é crime, com detenção de três meses a um ano. Consumado o fato, o militar sendo preso torna-se menos um a concorrer à escala de serviço.

Isto posto, o objetivo deste trabalho é otimizar a escala de serviço através da Programação Linear. Colin [13] afirma que, até a década de 1940, este método era de uso exclusivo das Forças Armadas na Segunda Guerra mundial, onde era de suma importância evitar erros e utilizar de forma inteligente os recursos que se encontravam escassos. Devido à 
sua grande eficiência, na década de 1950 começou a ser utilizado no ramo empresarial, gerando economias de milhões e até bilhões de dólares. A Programação Linear busca maximizar ou minimizar os recursos disponíveis de um problema, respeitando suas restrições, buscando a solução ótima.

A ferramenta utilizada foi o método Simplex. Baseado na Programação Linear, o Método Simplex é um algoritmo criado em 1947 por Dantzig (1914-2005), em que a cada iteração, busca achar a solução ótima. Segundo Loesch e Hein [14], o algoritmo Simplex pode ser estabelecido de acordo com os passos da Figura 1.

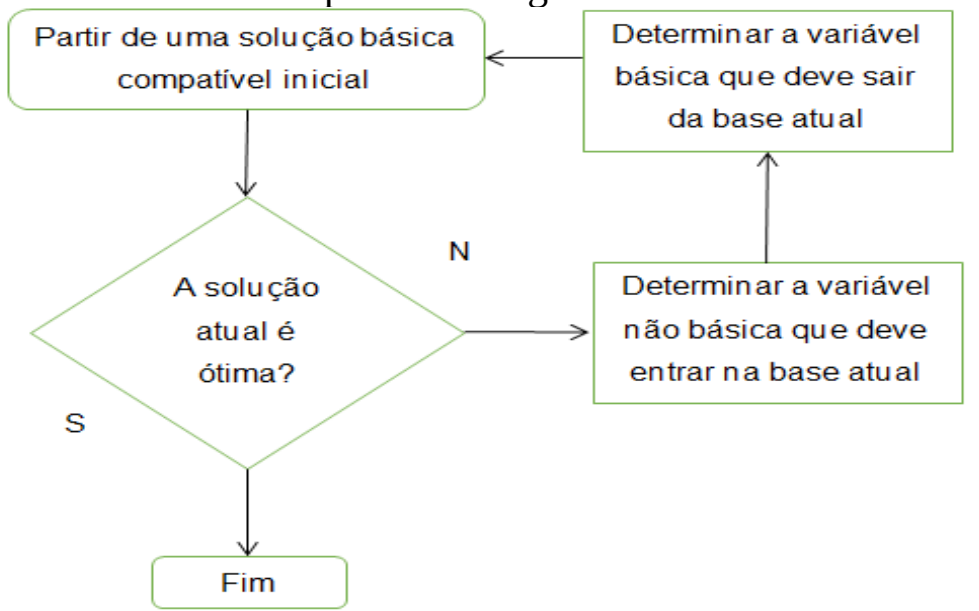

Figura 1 - Procedimentos para a construção do Simplex.

Quanto mais restrições ou variáveis há em um problema, maior será o cálculo e mais cansativo, estando suscetível a erros. Com o avanço da computação foi possível criar formas de solucionar o Simplex de forma rápida e confiável, como a ferramenta Solver do Excel.

Para modelar a Programação Linear foi necessário levantar os dados dos militares disponíveis a concorrer à escala de serviço durante todos os meses. Os dados coletados foram referentes às incorporações de 2016 a 2018. Após isto foi necessário classificar os postos de serviço segundo sua importância, e com base nestes dados foi criada a Função Objetivo e as Restrições do Método Simplex, a fim de otimizar o gargalo durante os meses com menor efetivo. Por fim, foi necessário analisar a viabilidade da solução ótima do problema.

\section{ESTUDO DE CASO}

\subsection{LEVANTAMENTO DE DADOS}

O estudo em questão foi realizado em uma OM do Rio de Janeiro, que em suas características, possui duas incorporações ao ano, chamadas de Alfa e Bravo com 123 recrutas cada uma, que cumprem seu serviço militar obrigatório de 10 a 11 meses.

O serviço começa às 08:00h e termina por volta das 10:00h do dia seguinte, e após isto, os militares saindo de serviço cumprem o expediente até às 17:00h. Apesar de estar escrito no RISG a recomendação de respeitar 48 horas de folga, o que é levado em consideração na contagem das folgas é a quantidade de pernoites. Independente de o serviço totalizar 26 horas e o militar ainda cumprir sua carga horária de trabalho até as 17:00h, o pernoite do dia posterior ao início do serviço contabiliza 24 horas, o pernoite do dia seguinte contabiliza 48 horas e assim sucessivamente.

Há 15 postos de serviço nesta OM, e cada posto precisa de três recrutas. Para respeitar a folga de $48 \mathrm{~h}$, seriam necessários nove recrutas para cada posto, como apresentado na Tabela 1. 
Se para cada posto são necessários nove recrutas, para quinze postos são necessários cento e trinta e cinco recrutas. As incorporações do Grupamento Alfa e Grupamento Bravo ocorrem em março e agosto respectivamente, tendo início às instruções e treinamentos quanto aos procedimentos do serviço e outras atividades militares, estando aptos a concorrer à escala de serviço 2 meses após à incorporação. Ambos os Grupamentos possuem duas baixas: a $1^{\text {a }}$ baixa ocorre com 10 meses e a $2^{\text {a }}$ baixa ocorre com 11 meses. Após a $2^{\mathrm{a}}$ baixa, restam apenas 123 recrutas, tendo um déficit de 12 recrutas para compor a escala de serviço. A Figura 2 apresenta a folga dos militares em cada mês e a linha vermelha representa o mínimo necessário.

\begin{tabular}{|c|c|c|c|c|c|c|c|}
\hline Dia/Militar & 1 & 2 & 3 & 4 & 5 & 6 & 7 \\
\hline $\operatorname{Rec} 001$ & SV & 1 & 2 & SV & 1 & 2 & SV \\
\hline Rec 002 & SV & 1 & 2 & SV & 1 & 2 & SV \\
\hline $\operatorname{Rec} 003$ & SV & 1 & 2 & SV & 1 & 2 & SV \\
\hline Rec 004 & & SV & 1 & 2 & SV & 1 & 2 \\
\hline Rec 005 & & SV & 1 & 2 & SV & 1 & 2 \\
\hline $\operatorname{Rec} 006$ & & SV & 1 & 2 & SV & 1 & 2 \\
\hline $\operatorname{Rec} 007$ & & & SV & 1 & 2 & sV & 1 \\
\hline $\operatorname{Rec} 008$ & & & SV & 1 & 2 & SV & 1 \\
\hline $\operatorname{Rec} 009$ & & & SV & 1 & 2 & sv & 1 \\
\hline Legenda & \multicolumn{7}{|c|}{$\begin{array}{l}\text { SV - o dia do serviço; } \\
1 \text { - o primeiro dia de folga ou } 24 \mathrm{~h} ; \\
2 \text { - o segundo dia de folga ou } 48 \mathrm{~h} \text {. }\end{array}$} \\
\hline
\end{tabular}

Tabela 1 - Exemplo de escala de serviço em condições mínimas.

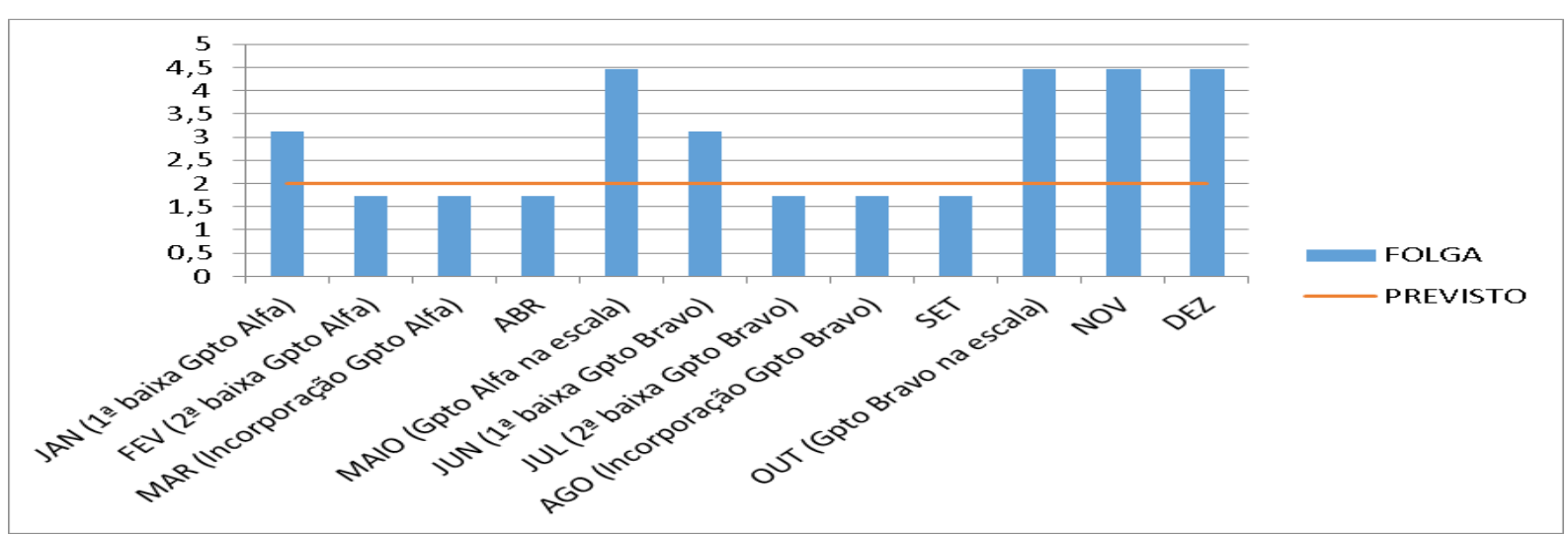

Figura 2 - Folga das sentinelas em cada mês

No entanto, destes 123 recrutas, alguns são destinados a outros serviços e alguns ficam afastados por motivos de saúde conforme apresentado na Tabela 2.

\begin{tabular}{|c|c|}
\hline Destino & Quantidade \\
\hline Rancho & 6 \\
\hline Pelotão de Obras & 3 \\
\hline Canil & 3 \\
\hline Enfermaria & 1 \\
\hline Baixados* & 8 \\
\hline Total & $\mathbf{2 1}$ \\
\hline
\end{tabular}

Tabela 2 - Quantidade de militares que não concorrem a escala de serviço.

\begin{tabular}{|c|c|}
\hline Incorporação & Baixados \\
\hline Alfa 2016 & 7 \\
\hline Bravo 2016 & 11 \\
\hline
\end{tabular}




\begin{tabular}{|c|c|}
\hline Alfa 2017 & 7 \\
\hline Bravo 2017 & 6 \\
\hline Alfa 2018 & 9 \\
\hline Bravo 2018 & 10 \\
\hline Média & $\mathbf{8 , 3 3}$ \\
\hline
\end{tabular}

Tabela 3 - Média de militares baixados.

O número de baixados foi obtido pelo arredondamento da média aritmética entre o número de baixados nos anos de 2016 a 2018, inclusive, considerando os grupamentos Alfa e Bravo dos respectivos anos, apresentado na Tabela 3.

Desta forma, restam somente 102 militares para concorrer à escala de sentinela, e noventa militares ficam com folga de vinte e quatro horas e um déficit de trinta e três recrutas na escala.

Para otimizar a escala de serviço com técnicas de Pesquisa Operacional através da Programação Linear, primeiro, foi necessário classificar cada posto por pesos, e para isto foram feitas as seguintes perguntas:

O posto faz parte do Plano de Defesa do Aquartelamento?

O posto é armado?

O posto é isolado?

\begin{tabular}{|c|c|c|c|c|c|c|c|}
\hline \multirow[b]{2}{*}{ Postos } & \multicolumn{2}{|c|}{ Faz parte do PDA? } & \multicolumn{2}{|c|}{ É armado? } & \multicolumn{2}{|c|}{ É isolado? } & \multirow[b]{2}{*}{ Média } \\
\hline & $\underset{\text { (10 pts) }}{\operatorname{Sim}}$ & $\begin{array}{l}\text { Não } \\
\text { (1 pt) }\end{array}$ & $\begin{array}{c}\text { Sim } \\
\text { (7 pts) }\end{array}$ & $\begin{array}{l}\text { Não } \\
\text { (1 pt) }\end{array}$ & $\begin{array}{c}\text { Sim } \\
\text { (5 pts) }\end{array}$ & $\begin{array}{l}\text { Não } \\
\text { (1 pt) }\end{array}$ & \\
\hline Reforço da Vila & \multicolumn{2}{|c|}{10} & \multicolumn{2}{|c|}{1} & \multicolumn{2}{|c|}{5} & 5,33 \\
\hline Posto Móvel da Vila & \multicolumn{2}{|c|}{10} & \multicolumn{2}{|c|}{1} & \multicolumn{2}{|c|}{5} & 5,33 \\
\hline Guarita da Vila & \multicolumn{2}{|c|}{10} & \multicolumn{2}{|c|}{1} & \multicolumn{2}{|c|}{5} & 5,33 \\
\hline PVP & \multicolumn{2}{|c|}{10} & \multicolumn{2}{|c|}{7} & \multicolumn{2}{|c|}{5} & 7,33 \\
\hline Atirador & \multicolumn{2}{|c|}{10} & \multicolumn{2}{|c|}{7} & \multicolumn{2}{|c|}{1} & 6 \\
\hline Guarita Sul & \multicolumn{2}{|c|}{10} & \multicolumn{2}{|c|}{7} & \multicolumn{2}{|c|}{5} & 7,33 \\
\hline Guarita da Área & \multicolumn{2}{|c|}{10} & \multicolumn{2}{|c|}{7} & \multicolumn{2}{|c|}{5} & 7,33 \\
\hline CCAp & \multicolumn{2}{|c|}{1} & \multicolumn{2}{|c|}{1} & \multicolumn{2}{|c|}{1} & 1 \\
\hline CDM & \multicolumn{2}{|l|}{1} & \multicolumn{2}{|c|}{1} & \multicolumn{2}{|c|}{1} & 1 \\
\hline Cia Sup & \multicolumn{2}{|l|}{1} & \multicolumn{2}{|c|}{1} & \multicolumn{2}{|c|}{1} & 1 \\
\hline 10 Pel & \multicolumn{2}{|l|}{1} & \multicolumn{2}{|c|}{7} & & & 4,33 \\
\hline 20 Pel & 1 & & 7 & & & & 4,33 \\
\hline 3o Pel & 1 & & 7 & & & & 4,33 \\
\hline PV 06 & 1 & & 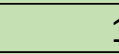 & & & & 2,33 \\
\hline PV 09 & 1 & & 1 & & & & 2,33 \\
\hline
\end{tabular}

Tabela 4 - Média de importância de cada posto de serviço.

Para conhecimento, Plano de Defesa do Aquartelamento, ou PDA, é um planejamento para situações de alterações ou perigos reais, onde cada militar é estrategicamente designado para um local pré-determinado, não podendo haver faltas.

A questão de o posto de serviço ser armado ou não foi levantada pela preocupação do desvio de armamento ou munições para o tráfico, tendo em vista o quartel em questão ser localizado em área com grande crescimento de milícias e facções criminosas. E a questão de o posto de serviço ser isolado cabe à preocupação da Força de Reação chegar ao local em casos de alterações reais.

Para as perguntas feitas para a elaboração da Tabela 4, foram atribuídas notas 10, 7, ou 5 respectivamente para respostas positivas e nota 1 para qualquer resposta negativa. As notas pré-estabelecidas foram determinadas a partir do grau de importância dos setores analisados, sem nenhuma referência básica. 
Para simplificar os cálculos da Programação Linear, os postos de serviço foram separados em quatro classes, segundo suas características, sendo estes:

$1^{\circ}$ - Guarda, com os postos que fazem parte do PDA;

$2^{\circ}$ - Plantões;

$3^{\circ}$ - Pelotões armados; e

$4^{\mathrm{o}}$ - Pelotões desarmados.

A Tabela 5 apresenta que com esta divisão, sete postos pertencem à classe Guarda, três postos pertencem à classe Plantões, três postos pertencem à classe Pelotões Armados e dois postos pertencem à classe Pelotões Desarmados.

\begin{tabular}{|c|c|c|}
\hline Classes & Postos & Média \\
\hline \multirow{7}{*}{ Guarda } & Reforço da Vila & \multirow{7}{*}{6,28} \\
\hline & Posto Móvel da Vila & \\
\hline & Guarita da Vila & \\
\hline & PVP & \\
\hline & Atirador & \\
\hline & Guarita Sul & \\
\hline & Guarita da Área & \\
\hline \multirow{3}{*}{ Plantões } & CCAp & \multirow{3}{*}{1} \\
\hline & CDM & \\
\hline & Cia Sup & \\
\hline \multirow{3}{*}{ Pelotões Armados } & 1ㅇ Pel & \multirow{3}{*}{4,33} \\
\hline & 20 Pel & \\
\hline & 3으 Pel & \\
\hline \multirow{2}{*}{ Pelotões Desarmados } & PV 06 & \multirow{2}{*}{2,33} \\
\hline & PV 09 & \\
\hline
\end{tabular}

Tabela 5 - Postos de serviço separados em classes.

\subsection{MODELAGEM E RESOLUÇÃO DA PROGRAMAÇÃO LINEAR}

Tendo as classes definidas, a Programação Linear será feita com o intuito de otimizar a escala de serviço através das médias atribuídas pelos pesos de importância. Para simplificar os cálculos, foram arredondadas a média da Guarda para 6, a média dos Plantões para 1, a média dos Pelotões Armados para 4 e a média dos Pelotões Desarmados para 2. Solução:

\section{(a) Variáveis de decisão:}

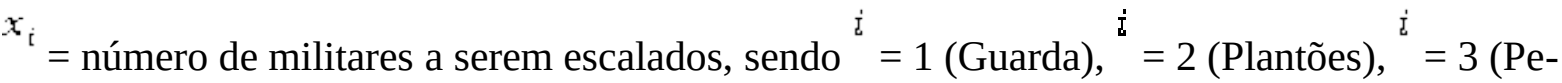
lotões Armados) $\mathrm{e}^{i}=4$ (Pelotões Desarmados).

(b) Função objetivo:

$\operatorname{Max} \mathrm{Z}=6^{x_{1}}+{ }^{x_{2}}+4^{x_{3}}+2^{x_{4}}$

(c) Restrições:

c.1) Efetivo total de militares disponíveis para a escala de serviço:

$$
x_{1}+x_{2}+x_{3}+x_{4} \leq 102
$$

c.2) Demanda de militares para a Guarda: 


$$
x_{1} \leq 63
$$

c.3) Demanda de militares para Plantões:

$$
x_{2} \leq 27
$$

c.4) Demanda de militares para os Pelotões Armados:

$$
x_{3} \leq 27
$$

c.5) Demanda de militares para os Pelotões Desarmados:

$$
x_{4} \leq 18
$$

c.6) Integralidade e não-negatividade:

$$
x_{1}, x_{2}, x_{3}, x_{4} \geq 0 \text { e inteiros. }
$$

Tendo a Função objetivo e as restrições definidas, aplicam-se estes dados na planilha Excel para ser resolvido através da ferramenta Solver, como demonstrado na Figura 3.

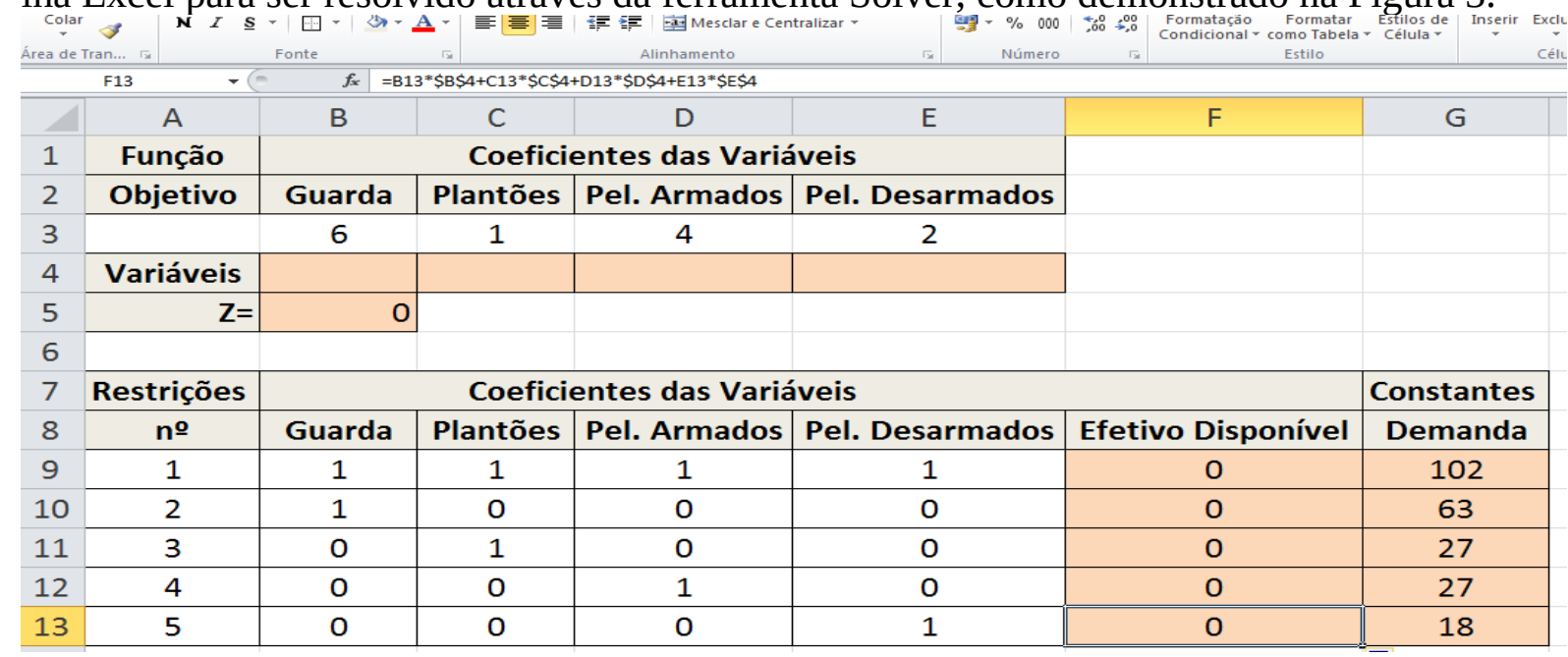

Figura 3 - Modelagem do problema no Excel.

A Solução Ótima proposta pela resolução do problema recomenda que sejam designados sessenta e três militares para a escala de Guarda $\left({ }^{x_{1}}\right)$, vinte e sete militares para a escala de Pelotões Armados $\left({ }^{x_{3}}\right)$ e doze militares para a escala de Pelotões Desarmados $\left({ }^{x_{4}}\right)$, conforme mostrado na Figura 4. 


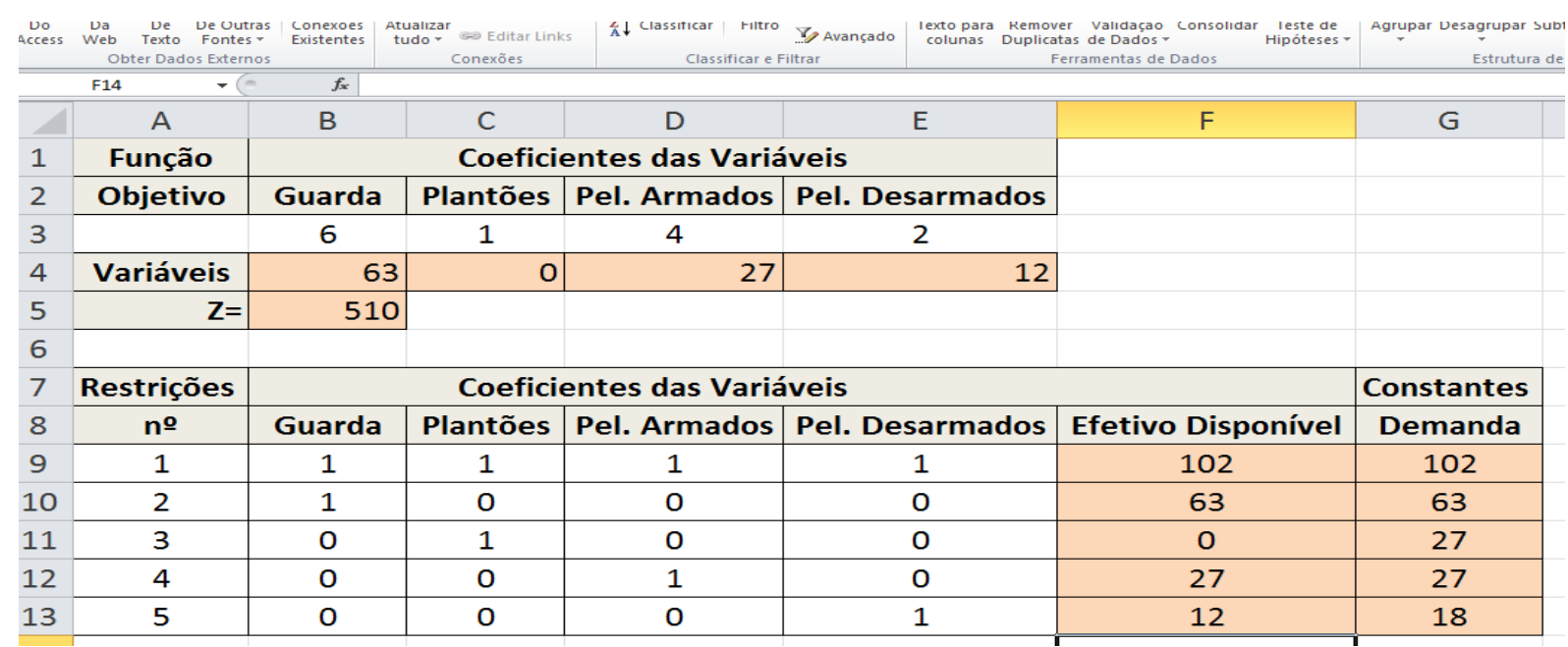

Figura 4 - Solução do problema.

\subsection{ANALISANDO A VIABILIDADE DA SOLUÇÃO DO PROBLEMA}

A demanda de militares para as escalas da Guarda e Pelotões Armados são 63 e 27 militares respectivamente, justamente a solução ótima do sistema. Sendo assim, não há necessidade de ajustar os postos destas classes.

A demanda de militares para os Pelotões Desarmados são 18 militares e a solução ótima foi 12 militares. Desta forma, faltam 6 militares para completar a folga de quarenta e oito horas.

Dentre os critérios de importância estabelecidos para os postos de serviço, há a opção se o posto é armado. Foi citado anteriormente que a OM em questão situa-se em área com crescimento constante de facções criminosas e milícias, com isto, é de suma importância que os Comandantes destes postos tenham atenção redobrada no controle de munições e armamentos para que não haja desvios para o crime.

A classe Pelotões Desarmados possui dois postos e um déficit de seis militares. Já que os Comandantes de ambos os postos não precisam fazer o controle de munições ou armamentos, é possível que eles assumam a função de sentinela cumulativamente com a função de comandante. Assim seria possível respeitar as quarenta e oito horas de folga, conforme Tabela 6.

Por fim, a solução não propôs o escalonamento de militares para os Plantões. Analisando o serviço de Plantão, ele fica desarmado e sua função é fazer a fiscalização para que não haja militares nos alojamentos durante o horário de expediente, a fim de minimizar ou evitar furtos de pertences individuais. Dentre suas funções também é manter o alojamento limpo, em condições de ser visitado por um Oficial Superior e verificar a situação de saúde dos militares que pernoitam no alojamento.

Sabendo de algumas funções dos Plantões, é possível evitar furtos instalando câmeras de segurança nos alojamentos, e já que o posto é desarmado e não fica isolado, é possível adiantar treinamentos com os recrutas recém-incorporados para exercer esta função já na primeira semana de internato durante as noites após as instruções. Por conta das instruções diurnas dos recém-incorporados, a manutenção dos alojamentos pode ser realizada pelos militares saindo de serviço.

\begin{tabular}{|c|c|c|c|c|c|c|c|}
\hline Dia/Militar & $\mathbf{1}$ & $\mathbf{2}$ & $\mathbf{3}$ & $\mathbf{4}$ & $\mathbf{5}$ & $\mathbf{6}$ & $\mathbf{7}$ \\
\hline Rec 001 & SV & 1 & 2 & SV & 1 & 2 & SV \\
\hline Rec 002 & SV & 1 & 2 & SV & 1 & 2 & SV \\
\hline Rec 003 & & SV & 1 & 2 & SV & 1 & 2 \\
\hline Rec 004 & & SV & 1 & 2 & SV & 1 & 2 \\
\hline
\end{tabular}




\begin{tabular}{|c|c|c|c|c|c|c|c|}
\hline Rec 005 & & & SV & 1 & 2 & SV & 1 \\
\hline Rec 006 & & & SV & 1 & 2 & SV & 1 \\
\hline Cmt 1 & SV & 1 & 2 & 3 & 4 & SV & 1 \\
\hline Cmt 2 & & SV & 1 & 2 & 3 & 4 & SV \\
\hline Cmt 3 & & & SV & 1 & 2 & 3 & 4 \\
\hline Cmt 4 & & & & SV & 1 & 2 & 3 \\
\hline Cmt 5 & & & & SV & 1 & 2 \\
\hline \multicolumn{7}{l}{$\begin{array}{l}\text { SV - o dia do serviço; } \\
\text { 1-o primeiro dia de folga ou 24h; } \\
\text { 2-o segundo dia de folga ou 48h; } \\
\text { 3-o terceiro dia de folga; } \\
\text { 4-o quarto dia de folga. }\end{array}$} \\
\hline
\end{tabular}

Tabela 6 - Exemplo da escala de serviço com o comandante fazendo as vezes de um sentinela.

\section{CONCLUSÃO}

Outras soluções foram estudadas para resolver o problema em questão. Uma delas seria incorporar 33 recrutas a mais por incorporação, já que a demanda para atender os 15 postos de serviço são 135 militares. Porém, levando em consideração que o soldo de um recruta é de $\mathrm{R} \$ 854,00$ (oitocentos e cinquenta e quatro reais), isto implicaria em um gasto de $\mathrm{R} \$ 28.182,00$ (vinte e oito mil, cento e oitenta e dois reais) mensais dos cofres públicos, somente com esta OM, já que o salário do Exército Brasileiro é pago pelo Governo Federal, fora os custos com transporte, alimentação, entre outros.

Pode-se descrever como outra solução, rebaixar cabos e soldados do efetivo profissional para compor a escala de sentinelas. Isto implicaria na redução nas escalas de comandantes de pequenas frações. Entretanto, a hierarquia e disciplina é levada à risca no Exército, e colocar antigos na mesma escala que recrutas poderia tirar o poder dos militares mais antigos e ocorreria desrespeito de seus subordinados.

Através da Programação Linear e análises dos postos de serviço, atingiu-se os objetivos pré-estabelecidos por esse estudo, encontrando a solução ótima levando-se em consideração a restrição (folga de quarenta oito horas) imposta pelo Inc. V do Art. 185 do Capítulo III do RISG. Para isto, foi preciso extinguir os postos de plantões e realizar um reajuste nos Pelotões Desarmados. Cabe ressaltar que estas alterações seriam realizadas somente nos meses em que o efetivo não atendesse a demanda dos postos de serviço.

Entretanto, esta proposta precisa ser aprovada pelo Subdiretor antes de ser empregada. Deve-se levar em consideração que este método aumentará a produtividade do expediente, já que aproximadamente $88 \%$ dos militares que concorrem à escala de sentinela ganharão uma noite a mais para descansarem e aproveitar o tempo com amigos e familiares e sem a necessidade de custos para o Governo Federal, conforme apresentado na Figura 5. 


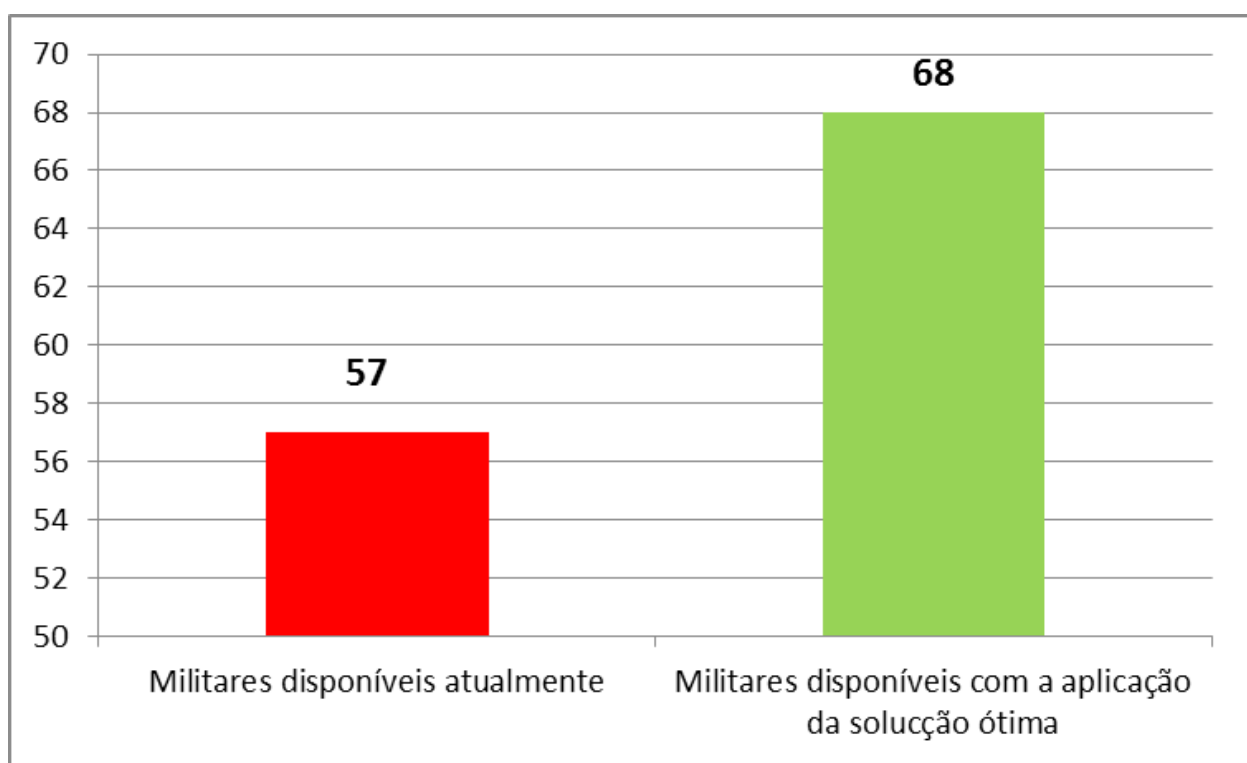

Figura 5 - Militares disponíveis para cumprir as missões de expediente diariamente

\section{REFERÊNCIAS BIBLIOGRÁFICAS}

[1] MARINS, Fernando Augusto Silva. Introdução à Pesquisa Operacional . São Paulo: Cultura Acadêmica : Universidade Estadual Paulista, Pró-Reitoria de Graduação, 2011.

[2] BELFIORE,P.; FÁVERO, L. P. Pesquisa Operacional para cursos de Engenharia. Rio de Janeiro: Elsevier, 2013.

[3] LONGARAY, André Andrade. Introdução à pesquisa operacional. 1. ed. São Paulo: Saraiva, 2013.

[4] BOSCHI, Giovana; FERREIRA, Carlos Roberto. Os desafios da escola pública paranaense na perspectiva do professor PDE 2016 Vol. 1 Versão Online ISBN 97885-8015-093-3. Paraná, 2016.

[5] BASSANEZI, R. C. Ensino-aprendizagem com modelagem matemática: uma nova estratégia. São Paulo: Contexto, 2011.

[6] BURAK, D. Modelagem Matemática: ações e interações no processo de ensino aprendizagem. Campinas, SP: 1992. Tese (Doutorado em Educação), Faculdade de Educação, Universidade Estadual de Campinas - UNICAMP.

[7] D’AMBROSIO, Ubiratan. Da realidade à ação reflexões sobre educação e matemática. 3 ed. Campinas: Summus Editora.1986.

[8] TAGUCHI, Américo Kunio. A integração da logística entre as forças singulares: uma concepção. Trabalho de Conclusão de Curso (Especialização em Ciências Militares). Escola de Comando e Estado-Maior do Exército, Rio de Janeiro, 1999.

[9] MCGINNIS, M.A. Military logistics. International Journal of Physical Distribution \& Logistics Management, Bradford, v.22, n.2, p.22-32, Apr. 1992.

[10] ANDREUZZA M. Planejamento estratégico. Sagres: Política e gestão estratégica aplicada, Paraná. 2012.

[11] VAlEnTIM, Marta. Planejamento Tático e Operacional. Marília: Universidade Estadual Paulista, 2018. 
[12] MARTINS, Lilian Cristina Xavier.; KUHN, Leandro. Prevalência de transtornos mentais comuns em jovens brasileiros recém-incorporados ao Serviço Militar Obrigatório e fatores associados. Escola de Educação Física do Exército, 2012.

[13] COLIN, Emerson C. Pesquisa operacional : 170 aplicações em estratégia finanças, logística, produção, marketing e vendas. 2. ed. São Paulo: Atlas, 2018.

[14] LOESCH, Claudio.; HEIN, Nelson. Pesquisa operacional : fundamentos e modelos. São Paulo: Saraiva, 2009. 